\title{
Movement behaviour and video tracking of Milnesium tardigradum Doyère, 1840 (Eutardigrada, Apochela)
}

\author{
Denis Shcherbakov ${ }^{1,3}$, Ralph O. Schill ${ }^{2}$, Franz Brümmer ${ }^{2}$, Martin Blum ${ }^{1}$ \\ ${ }^{1}$ Institute of Zoology, University of Hohenheim, 70593 Stuttgart, Germany \\ ${ }^{2}$ Institute of Biology, Zoology, University of Stuttgart, 70569 Stuttgart, Germany \\ ${ }^{3}$ E-mail:dscher@uni-hohenheim.de
}

Key words: locomotion, Tardigrada, video analysis

\begin{abstract}
Tardigrades or 'water-bears' live in moist environments with a high degree of gaseous exchange. In tardigrades, locomotion is essential, e.g. for feeding, to find sexual partners and to adjust the level of hydration by moving to wetter or dryer environments. Here we report on the movement behaviour of Milnesium tardigradum in automated experiments using custom-made video tracking software. The experiments involved 754 hours of recording involving 32 individuals. No significant differences in mobility were observed under infrared versus visible light conditions, representing night and day, respectively. The mean recorded velocity was $23.3 \pm 7.38 \mathrm{~mm} / \mathrm{h}$, with a maximum of $1166.4 \mathrm{~mm} / \mathrm{h}$.
\end{abstract}

\section{Contents}

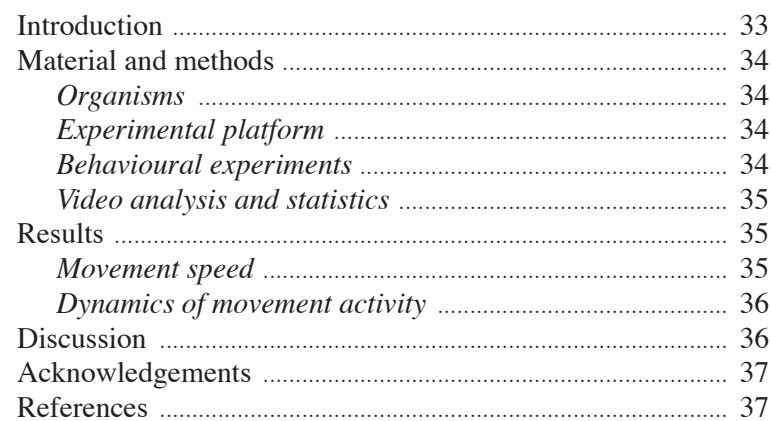

\section{Introduction}

In recent years the phylum Tardigrada has been expanded by several new taxa and increased to more than 960 species, but the number of described species still increases quickly every year (Guidetti and Bertolani, 2005; Degma and Guidetti, 2007). Despite their overall abundance tardigrades have received little scientific attention, particularly their physiology and behaviour, in the last 200 years. The name tardigrade describes their movement (Lat. tardus-slow, gradi-walker) and was assigned in the $18^{\text {th }}$ century by Lazzaro Spallanzani, who also carried out pioneer studies on their 'resurrection' (cryptobiosis) (Spallanzani, 1776).

Although there are several studies on tardigrades to understand the mechanisms of dehydration and freezing in embryonic and adult specimens (Ramløv and Westh, 1992; Westh and Kristensen, 1992; Sømme, 1996; Jönsson, 2001; Jönsson et al., 2001; Wright, 2001; Nelson, 2002; Rebecchi et al., 2006; Hengherr et al., 2008, 2009a, 2009b; Schill and Fritz, 2008; Schill et al., 2009), only limited data have been generated to understand their ecology. In addition, little attention has been devoted to the life-history of tardigrades (Von Wenck, 1914; Baumann, 1961, 1964, 1966, 1970; Dougherty, 1964; Suzuki, 2003; Altiero et al., 2006) and their adaptive behaviour (Nelson and Adkins, 2001; Wright, 2001; Xiaochen and Wang, 2005; Altiero et al., 2006). Terrestrial tardigrades live in a thin film of water on the surface of moss, lichens, algae, and other plants and depend on water to remain active and complete their life cycle. In these habitats tardigrades can survive desiccation during dry spells by contracting into a regular-shaped 'tun' state (Baumann, 1922, 1927). However, this can only occur when they are slowly dehydrated within an environment of high humidity (Crowe, 1975). Thus locomotion in fast changing microhabitats is the single most important determinant of animal behaviour to control dehydration and rehydration. In addition, Milnesium tardigradum Doyère, 1840 and Macrobiotus richtersi Murray, 1911 actively hunt their prey (Hohberg and Traunspurger, 2005; Hengherr et al., 2008).

Observation of motion and locomotion patterns in their natural habitat is not possible. However, previous studies with artificial or at best semi-natural conditions were performed in the late 1920s by Marcus (1928), who estimated the maximal rate of movement at 30-50 
$\mu \mathrm{m} / \mathrm{s}$ for Echiniscus and $100 \mu \mathrm{m} / \mathrm{s}$ for Batillipes and Milnesium. Later observations by videotaping were carried out to investigate the movement behaviour of Macrobiotus sp. and Echiniscus testudo (Doyère, 1840) on single stems of mosses with differing water retaining capacities and to observe the general pattern of tardigrade leg movement (Schüttler and Greven, 2000/2001). To understand the life-history and habitat preferences of terrestrial tardigrades it is, however, necessary to acquire data from behavioural experiments. We therefore focused our study on speed and direction of the locomotion in an artificial system during simulated day and night conditions for the tardigrade species $M$. tardigradum.

\section{Material and methods}

\section{Organisms}

Tardigrades of the species $M$. tardigradum Doyère, 1840 (Eutardigrada, Apochela) were cultured in the laboratory in plastic culture dishes with a thin layer of agar, covered with Volvic ${ }^{\mathrm{TM}}$ water (Danone Waters Deutschland, Wiesbaden, Germany). The animals were fed rotifers of the species Philodina citrina Ehrenberg, 1832 which were raised on the green algae Chlorogonium elongatum (Dangeard, 1897). Young tardigrades were additionally fed green algae $C$. elongatum. We used animals from a parthenogenetic population, which was previous collected in Tübingen, Germany, and cultured over several years in an environmental chamber at $20^{\circ} \mathrm{C}$ using an artificial light source with a $12 \mathrm{~h}$ light $/ 12 \mathrm{~h}$ dark cycle. The age of the tested tardigrades was approximately 40 days and the animals had a mean body size of about $1 \mathrm{~mm}$.

\section{Experimental platform}

For the behavioural experiments and the observation of the specimens a simple 'arena' construction was developed (Fig. 1). For this purpose 36 openings were drilled through a plexiglas plate to form the arena grid, with each individual 'arena' having a diameter of $7 \mathrm{~mm}$. Preliminary tests showed that the optimal adhesive material for fixing the 'arena' grid was hot paraffin wax. The surface of paraffin is rough (not slippery as normal Petri dishes), so this material seemed to be suitable for the movement of tardigrades using their clawed limbs without further adaptation.

\section{Behavioural experiments}

The behavioural experiments were carried out in a room with constant climate conditions controlled by a climate control system and using a video tracking system. For the experiments the Petri dish with arena grid was positioned on a custom-made infrared light table and filled with Volvic ${ }^{\mathrm{TM}}$ water (Fig. 1). Thereafter, well fed animals were placed individually into each 'arena',

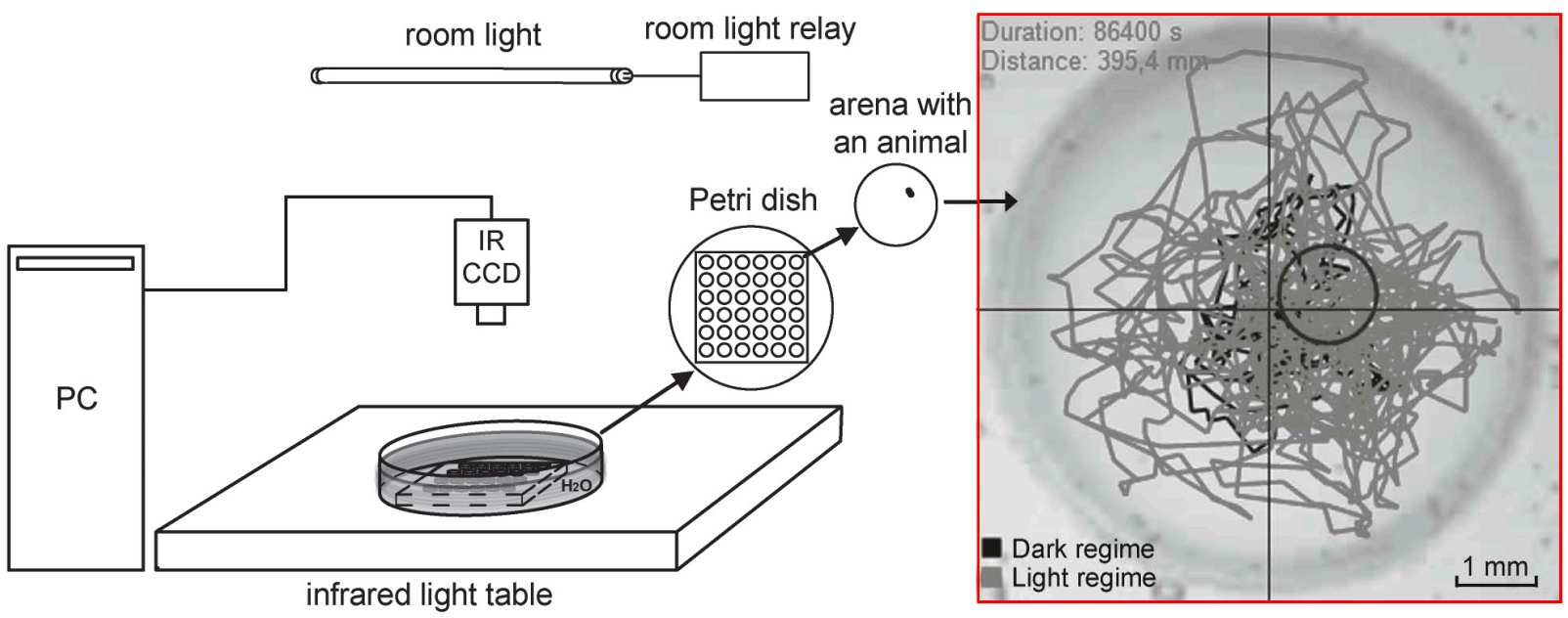

Fig. 1. Schematic representation of a video tracking system for the automated analysis of animal movement behaviour. The right part of the figure shows an example trajectory of an individual of $M$. tardigradum over the first 24-hour period. The circle indicates the last position of the animal (see embedded supplementary video). 
Table $1 a-b$. a) Movement behaviour of M. tardigradum during the light and dark regime. b) Movement behaviour of M. tardigradum during the first and second periods of observation.

\begin{tabular}{|c|c|c|c|c|}
\hline a) & parameter & light regime & dark regime & number of animals \\
\hline & mean speed $(\mathrm{mm} / \mathrm{h})$ & $19.8 \pm 10.4$ & $29.0 \pm 11.1$ n.s. & 22 \\
\hline \multirow[t]{3}{*}{ b) } & parameter & first observation period & second observation period & number of animals \\
\hline & spatial rate of change of direction $(\% / \mathrm{mm})$ & $241.4 \pm 21.3$ & $180.6 \pm 20.1 * * *$ & 31 \\
\hline & mean speed $(\mathrm{mm} / \mathrm{h})$ & $14.4 \pm 7.6$ & $31.0 \pm 8.7 * *$ & 31 \\
\hline
\end{tabular}

and the behaviour of tardigrades was recorded using an infrared sensitive camcorder (Sony DCR-HC23E). For the duration of the experiments the infrared light table was left $\mathrm{ON}$ to produce the optimal illumination for the infrared camcorder. The only visible light (daytime) was emitted by a standard halogen lamp of type 'Philips TLD $58 \mathrm{~W}$ ' with the colour temperature of $4000 \mathrm{~K}$. The intensity of illumination in the experimental area was measured at 200 lux. The room lightning was controlled by an automated relay. The working mode of visible light was $12 \mathrm{~h}$ ON (light regime), $12 \mathrm{~h}$ OFF (dark regime). For capturing and saving of video information the freely available software VirtualDub (http://www.virtualdub.org) was used. The video was recorded directly to the hard drive of a computer system at 25 frames per second, and because of the small size of the animals $(\leq 1 \mathrm{~mm})$ it was possible to record two arenas simultaneously by one camcorder.

\section{Video analysis and statistics}

The sampled videos were analysed using the custom made video tracking software "BioMotionTrack D.S.", programmed by D. Shcherbakov. Analysis of animal movements by our video tracking program was based on an automated body contours recognition algorithm. The software calculated the location coordinates of the animals, their movement speed and length of the tracks, portion of time in different areas of the arenas, and angle of movement direction. Due to the very slow movement and speed of the animals it was sufficient to analyse 1 frame per 10 second of the original video source. A video file with the animal tracks was created as a result of this calculation (see Fig. 1, embedded supplementary video and calculated data were saved as '.asc'-text. These results were imported into Access (Microsoft) database for data management and analysis. The calculation of statistical significance was carried out by Wilcoxon matched pairs test (Statistica 6.1
- StatSoft, Inc). Significance levels were $P \geq 0.05$ (not significant), $0.05>P \geq 0.01$ (weakly significant $*$ ), $0.01>P \geq 0.001$ (significant $* *$ ), and $P<0.001$ (highly significant $* * *)$.

\section{Results}

For the statistical analysis of the mean speed $[\mathrm{mm} / \mathrm{h}]$ under light and dark regimes the results of 22 animals were used (Fig. 2, Table 1a), and for the spatial rate of direction change $[\% / \mathrm{mm}]$ and the mean speed $[\mathrm{mm} / \mathrm{h}]$ we divided the total period of observation into first and second intervals (Fig. 2). For this a total of 31 animals were observed (Table 1b).

\section{Movement speed}

The mean speed of tested animals during the first observation period was $14.4 \pm 7.6 \mathrm{~mm} / \mathrm{h}$, and during the second period $31.0 \pm 8.7 \mathrm{~mm} / \mathrm{h}$ (Table $1 \mathrm{~b}$ ). The maximum total distance travelled by an individual was measured as $1,799.3 \mathrm{~mm}$ during 37 hours with a mean speed of $48.6 \pm 8.99 \mathrm{~mm} / \mathrm{h}$. On the other hand, the fastest individual of $M$.tardigradum covered a distance of $1,365.6 \mathrm{~mm}$ during 6 hours with a mean speed of 227.6 $\pm 6.64 \mathrm{~mm} / \mathrm{h}$. One individual's maximum burst of speed was measured at $1,166.4 \mathrm{~mm} / \mathrm{h}$ for 10 seconds. In $24.8 \%$ of the recorded time ( 187 hours) the animals showed no movement at all. During $64.3 \%$ (485 hours) of the time recorded the mean speed was higher than 0 and $\leq 50 \mathrm{~mm} / \mathrm{h}$, while in the remaining $10.9 \%$ (82 hours) of the time specimens were on average faster than $50 \mathrm{~mm} / \mathrm{h}$. Under the light regime tardigrades showed a mean speed of $19.8 \pm 10.4 \mathrm{~mm} / \mathrm{h}$, and under infrared light illumination (dark regime) mean speed increased to $29.0 \pm 11.1 \mathrm{~mm} / \mathrm{h}$ (Table $1 \mathrm{a}$ ). This difference, however, was not statistically significant $(\mathrm{p}=0.14)$, due mostly to the high variance between individual specimens. 


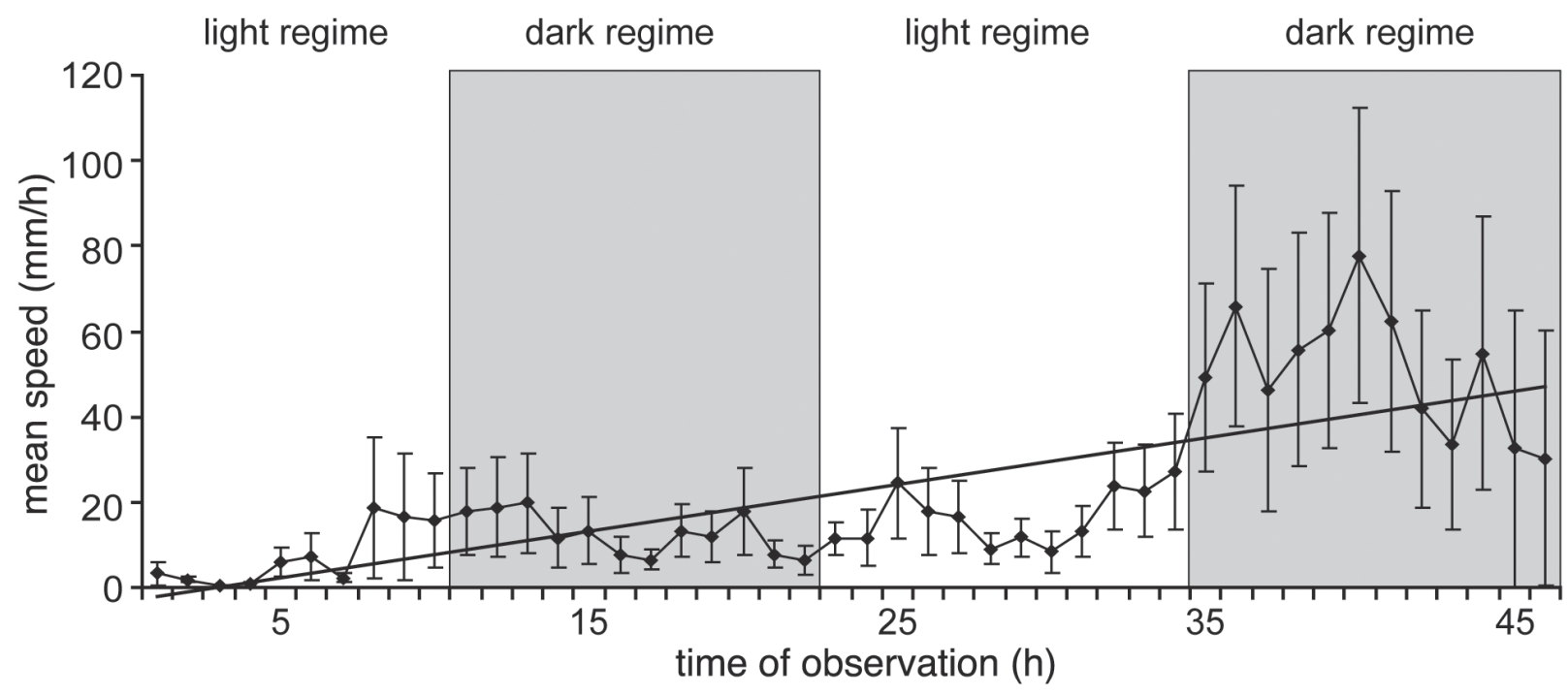

Fig. 2. The dynamics of movement activity for M.tardigradum are based on the analysis of 22 animals with light and dark regimes.

\section{Dynamics of movement activity}

The calculations for 31 individuals showed that after the first observation period the speed of movement increased (Table 1b), and this difference was statistically highly significant. For characterization of tardigrade movement directionality, the angles $\left(^{\circ}\right)$ of direction changes between successive movements were calculated (turning angle). The mean summarized turning angles per hour for the second period were 3,067 \pm $631.62^{\circ}, 1.8$ times higher than in the first period $(1,667$ $\left.\pm 511.88^{\circ}\right)$. The animals changed direction more often with the increased movement activity of the second observation period. This increase in the mean summarized turning angles per hour was also statistically highly significant.

For the analysis of the rate of direction change (Benhamou and Bovet, 1989) the mean turning angle $\left(^{\circ}\right)$ per $\mathrm{mm}$ of covered distance was calculated. During the first observation period the animals showed predominantly oscillating movements with a higher rate of direction change $\left(241.4 \pm 21.3^{\circ} / \mathrm{mm}\right)$. During the second observation period the rate of direction change was significantly lower $\left(180.6 \pm 20.1^{\circ} / \mathrm{mm}\right)$ (Table $\left.1 b\right)$.

\section{Discussion}

Marcus (1929) observed a positive phototaxic response for the heterotardigrades Batillipes mirus Rich- ters, 1909 and Echiniscoides sigismundi (Schultze, 1865) but negative phototaxis for the eutardigrade Dactylobiotus dispar (Murray, 1907). The intensity of light also seemed to be an important factor, because the eutardigrade Pseudobiotus megalonyx (Thulin, 1928) was more likely to show negative phototaxis to direct sunlight but positive phototaxis to more diffuse light. However, until now all published studies represent observations without an automatic long-term video tracking system, and the visual abilities of tardigrades are so far unknown.

In our experiments $M$. tardigradum showed a quite low mean speed during the whole period of observation $(23.3 \pm 7.38 \mathrm{~mm} / \mathrm{h} \approx 23$ body lengths $/ \mathrm{h})$, in perfect agreement with the Latin etymology of the phylum name - 'slow walker'. Nevertheless, the maximal burst of speed was quite high $(1,166.4 \mathrm{~mm} / \mathrm{h})$ for an animal with such a small body size, i.e. they moved at $\sim 1166$ body lengths/ $\mathrm{h}$, although only for a very short time span of a few seconds. We suppose that the fast movements could be used by the animals to react quickly to environmental stimuli.

The reason for the different locomotion patterns and speed of individual animals is unclear. In just a quarter of the observation time M. tardigradum was passive and showed no mobility. As the animals were fed before the observation was started, the stimulation to move around for prey should be reduced. This phenomenon has also been reported for the species $M$. richtersi where some individuals after feeding on 
nematodes had to rest for a variable amount of time, while other animals fed more slowly and continuously without a break (Hohberg and Traunspurger, 2005).

We observed that the movements of individual tardigrades accelerated twice after the first observation period, which may be explained by stimuli for motion, in this case most likely that of hunger. Analysis of the dynamics of the walking speed showed an orthokinetic form of movements, i.e. animals change their speed of movement depending on environmental stimuli. Thus under favourable conditions movement will be slower due to the absence of motivation to leave a preferred area. Similar examples for orthokinetic locomotion behaviour were observed for woodlice with their search for high humidity habitats (Fraenkel and Gunn, 1961) and by ants searching for feeding places (Durou et al., 2001).

The lower rate of direction change, shown after the first observation period, leads to straighter trajectories and thus allows an animal to leave an unfavourable area more quickly - in this case an area with no food. The change in the movement turning intensity $(\% / \mathrm{h}$ and $\% / \mathrm{mm}$ ) indicated a klinokinetic behaviour pattern by tardigrades. By klinokinesis animals change their frequency of movement direction depending on the environmental variability (Merkel, 1980). Our results are thus in agreement with the observation that animals show an increase in rate of direction change to stay within a more favourable area and decrease rate of direction change to move away from an unfavourable area (Codling et al., 2008).

In $M$. tardigradum, the analysis of the automated tracking did not reveal any significant differences between the movement speed during the light and dark regimes. This does not mean that light conditions have no effect on the movement activities of this species, but rather the animals can be very active under both light conditions and show no light dependent resting period. Young individuals of the species Macrobiotus cf. hufelandi exhibited a negative response to light, while animals larger than $120 \mu \mathrm{m}$ exhibit neither negative or positive responses (Beasley, 2001). Beasley assumed that animals smaller than $120 \mu \mathrm{m}$ avoid light to protect themselves from desiccation due to the disadvantageous surface area-to-volume ratio. We have not tested whether young animals of M.tardigradum show similar behaviour, but their ability to cope with desiccation is already developed in embryos (Schill and Fritz, 2008), so it could be possible.

We feel this study revealed novel insights in the ecology and behaviour of M. tardigradum, and the use of an automated video tracking system opens a wide range of possibilities for future behavioural studies on other members of this phylum.

\section{Acknowledgements}

We like to thank Sybille Wolf, Eva Roth, Steffen Hengherr, and Thomas Weber for their assistance. And we wish to thank Sandra McInnes for the helpful advice and critical discussion on the manuscript. This study was a part of the project FUNCRYPTA (0313838A), funded by the German Federal Ministry of Education and Research, BMBF.

\section{References}

Altiero T, Rebecchi L, Bertolani R. 2006. Phenotypic variations in the life history of two clones of Macrobiotus richtersi (Eutardigrada, Macrobiotidae). Hydrobiologia 558: 33-40.

Baumann H. 1922. Die Anabiose der Tardigraden. Zoologische Jahrbücher 45: 501-556.

Baumann H. 1927. Anabiosis of tardigrades. Zoologischer Anzeiger 72: 175-179.

Baumann H. 1961. Der Lebensablauf von Hypsibius (H.) convergens Urbanowicz (Tardigrada). Zoologischer Anzeiger 167: 363-381.

Baumann H. 1964. Über den Lebenslauf und die Lebensweise von Milnesium tardigradum Doyère (Tardigrada). Veröffentlichungen aus dem Überseemuseum Bremen 3: 161-171.

Baumann H. 1966. Lebenslauf und Lebensweise von Hypsibius (H.) oberhaeuseri Doyère (Tardigrada). Veröffentlichungen aus dem Überseemuseum Bremen 3: 245-258.

Baumann H. 1970. Lebenslauf und Lebensweise von Macrobiotus hufelandi Schultze (Tardigrada). Veröffentlichungen aus dem Überseemuseum Bremen 4: 29-43.

Beasley C. 2001. Photokinesis of Macrobiotus hufelandi (Tardigrada, Eutardigrada). Zoologischer Anzeiger 240: 233-236.

Benhamou S, Bovet P. 1989. How animals use their environment: a new look at kinesis. Animal Behaviour 38: 375-383.

Codling EA, Plank MJ, Benhamou S. 2008. Random walk models in biology. Journal of the Royal Society Interface 5: 813-834.

Crowe JH. 1975. The physiology of cryptobiosis in tardigrades. Memorie dell'Istituto Italiano di Idrobiologia Dott Marco de Marchi 32: 37-59.

Degma P, Guidetti R. 2007. Notes to the current checklist of Tardigrada. Zootaxa 1579: 41-53.

Dougherty E. 1964. Cultivation and nutrition of micrometazoa. II. An Antarctic strain of the tardigrade Hypsibius arcticus (Murray, 1907) Marcus, 1928. Transactions of the American Microscopical Society 83: 7-11.

Durou S, Lauga J, DeJean A. 2001. Intensive food searching in humid patches: adaptation of a myrmicine ant to environmental constraints. Behaviour 138: 251-259.

Fraenkel GS, Gunn DL. 1961. The Orientation of Animals. New York: Dover Publications Inc.

Guidetti R, Bertolani R. 2005. Tardigrade taxonomy: an updated check list of the taxa and a list of characters for their identification. Zootaxa 845: 1-46. 
Hengherr S, Brümmer F, Schill RO. 2008. Anhydrobiosis in tardigrades and its effects on longevity traits. Journal of Zoology (London) 275: 216-220.

Hengherr S, Reuner A, Worland R, Brümmer F, Schill RO. 2009a. Freeze tolerance, super cooling points and ice formation: comparative studies on the subzero temperature survival of limno-terrestrial tardigrades. Journal of Experimental Biology 212: 802-807.

Hengherr S, Worland MR, Reuner A, Brümmer F, Schill RO. 2009b. High-temperature tolerance in anhydrobiotic tardigrades is limited by glass transition. Physiological and Biochemical Zoology 82: 749-755.

Hohberg K, Traunspurger W. 2005. Predator-prey interaction in soil food web: functional response, size-dependent foraging efficiency, and the influence of soil texture. Biology and Fertility of Soils 41: 419-427.

Jönsson KI. 2001. The nature of selection on anhydrobiotic capacity in tardigrades. Zoologischer Anzeiger 240: 409-417.

Jönsson KI, Borsari S, Rebecchi L. 2001. Anhydrobiotic survival in populations of the tardigrades Richtersius coronifer and Ramazzottius oberhaeuseri from Italy and Sweden. Zoologischer Anzeiger 240: 419-423.

Marcus E. 1928. Spinnentiere oder Arachnoidea IV: Bärtierchen (Tardigrada). Jena: Springer.

Marcus E. 1929. Tardigrada. Pp. 1-608 in: Bronn HG, Klassen und Ordnungen des Tierreichs, vol. 5, sect. 4, book 3. Leipzig: Akademische Verlagsgesellschaft.

Merkel FW. 1980. Orientierung im Tierreich. Stuttgart, New York: Gustav Fischer Verlag.

Nelson DR. 2002. Current status of the tardigrada: evolution and ecology. Integrative and Comparative Biology 42: 652-659.

Nelson DR, Adkins RG. 2001. Distribution of tardigrades within a moss cushion: Do tardigrades migrate in response to changing moisture conditions? Zoologischer Anzeiger 240: 493-500.

Ramløv H, Westh P. 1992. Survival of the cryptobiotic eutardigrade Adorybiotus coronifer during cooling to $-196^{\circ} \mathrm{C}$ : effect of cooling rate, trehalose level, and short-term acclimation. Cryobiology 29: 125-130.
Rebecchi L, Guidetti R, Borsari S, Altiero T, Bertolani R. 2006. Dynamics of long-term anhydrobiotic survival of lichendwelling tardigrades. Hydrobiologia 558: 23-30.

Schill RO, Fritz GB. 2008. Desiccation tolerance in embryonic stages of the tardigrade Milnesium tardigradum. Journal of Zoology (London) 276: 103-107.

Schill RO, Mali B, Dandekar T, Schnölzer M, Reuter D, Frohme M. 2009. Molecular mechanisms of tolerance in tardigrades: new perspectives for preservation and stabilization of biological material. Biotechnology Advances: 348-352.

Schüttler L, Greven H. 2000/2001. Beobachtungen zur Lokomotion von Tardigraden. Acta Biologica Benrodis 11: 33-52.

Sømme L. 1996. Anhydrobiosis and cold tolerance in tardigrades. European Journal of Entomology 93: 349-357.

Spallanzani L. 1776. Opuscoli di fisica animale e vegetabile. Modena: Presso la Società Tipografica.

Suzuki AC. 2003. Life history of Milnesium tardigradum Doyere (Tardigrada) under a rearing environment. Zoological Science (Tokyo) 20: 49-57.

Von Wenck W. 1914. Entwicklungsgeschichtliche Untersuchungen an Tardigraden (Macrobiotus lacustris Duj.). Zoologische Jahrbücher 37: 465-514.

Westh P, Kristensen RM. 1992. Ice formation in the freeze-tolerant eutardigrades Adorybiotus coronifer and Amphibolus nebulosus studied by differential scanning calorimetry. Polar Biology 12: 693-699.

Wright JC. 2001. Cryptobiosis 300 years on from Van Leeuwenhoek: what have we learned about tardigrades? Zoologischer Anzeiger 240: 563-582.

Xiaochen L, Wang L. 2005. Effect of temperature and thermal acclimation on locomotor performance of Macrobiotus harmsworthi Murray (Tardigrada, Macrobiotidae). Journal of Thermal Biology 30: 588-594.

Received: 28 May 2009

Accepted: 22 January 2010

Published online: 5 March 2010

Editor: J.W. Arntzen 